\title{
Effect of sports training programme on juvenile sports dancers motivation
}

\author{
Uspuriene B.A. ${ }^{1,2 \mathrm{ABCDE}}$, Sniras S.A. ${ }^{3 \mathrm{ABCDE}}$ \\ ${ }^{1}$ Department of Coaching Science, Lithuanian Sports University, Lithuania \\ ${ }^{2}$ Institute of Education, Vytautas Magnus University, Lithuania \\ ${ }^{3}$ Department of Health, Physical and Social Education, Lithuanian Sports University, Lithuania
}

Authors' Contribution: A - Study design; B - Data collection; C - Statistical analysis; D - Manuscript Preparation; E - Funds Collection.

\begin{abstract}
Purpose: Lately, the researchers have paid more and more attention to the issues of sport motivation of exercising schoolchildren, but there are few scientific studies drawing the attention of researchers to sports training programme effect on juvenile sports dancers motivation.

Purpose: to verify the effectiveness of sports training programme on the expression of juvenile (9-11 years old) sports dancers sport motivation.

Material: $\quad$ A scheme of the research of three groups was applied by using the initial and final measurements. The initial research was performed before the experiment and the final research was performed after the experiment, during the sports practice by using the sport motivation scale (SMS). 54 junior (9-11) dancers participated in the pedagogic experiment and they were divided into three groups: EG-1 - first experimental group, EG-2 - second experimental group, CG - control group. Each group consisted of 9 girls and 9 boys. The groups that participated in the experiment performed sports training programmes with the different diversity of methods and means. Kholmogorov - Smirnov test and Wilcoxon Z criterion were used for the descriptive index analysis in order to compare two independent samples.

Results: $\quad$ The results of the research showed that the expression of the sport motivation-indicating subscales increased statistically significantly in groups EG-1 and EG-2 of juvenile (9-11) dancers in the 12-week period of the pedagogic experiment: "to find out ", "to strive for perfection“, „to experience“. The intensity of the subscale of "amotivation" did not increase statistically reliably in the period of the pedagogic experiment $(p>0,05)$. Moreover, it was determined that the internal motivation-indicating subscale "to strive for perfection" was the most expressed in the junior dancers.

Conclusions: the diversity of sports training methods and means applied during the pedagogic experiment had a positive influence on the expression of sport motivation in the juvenile (9-11) dancers. After the sports training programmes, there were statistically significant changes in the both experimental groups in relation with the effect of the sports training programme according to the expression of the internal motivation-indicating subscales: "to find out", "to strive for perfection" "to experience" and of the external motivation-indicating subscales: "direct external regulation" and "to identify, synchronize“.

Keywords: $\quad$ sport motivation, sports training programme, sports dancers, dancers.
\end{abstract}

\section{Introduction $^{1}$}

The training of juvenile dancers oriented to the striving of sports results is related with the realization of motor abilities by improving the mastery, with the emotional satisfaction on dancing and with the training of artistic abilities to express the idea of dancing with body movements [1, 2]. There is an important theoretic assumption that the content of training depends on the child's age [3, 4], so it is necessary to pay much attention to juvenile dancers in the initial stage of long-term development when the basis is created for the improvement of dancers mastery [5,6]. Analysing scientific references, we missed the rules of the effect of dancers' training means (contents of practice) on the sports preparedness of juvenile dancers. The researchers state that children are very active in the period of the middle childhood (9-11) and they participate willingly in such sports activities as games and relay races [7-9]. The researchers of dances [10-12] state that different dance styles with the most various moves should be applied in the initial stage of (c) Uspuriene B.A., Sniras S.A., 2018

doi:10.15561/18189172.2018.0308 training of juvenile dancers. Just constant modelling of athlete's training programmes enables optimizing the preparedness of athletes that conditions sports results [13]. It was impossible to find a model of juvenile dancers training that would help to develop the sport motivation of athletes and be based on the theory of athlete's control stating that the management of training of athletes involving the training, monitoring, preparedness and feedback allows training athletes single-mindedly; it was impossible to find a model on which basis the training of juvenile dancers would be designed and managed [1416]. Moreover, we think the model of training of this sport with the signs of expression of sports and art should reflect the combination of training means and methods with the factors reflecting the needs of juvenile dancers and strengthening their internal motivation.

However, the act of athletes training, which main axis is an athlete, is closely related with the motivation of dancers to become more perfect, win and be acknowledged. The encouragement of motivation for physical activity and the chosen sport takes an important place in the initial stage 
of juvenile dancers training $[17,18]$. The particularity of dance sport also encourages strengthening the motivation of juvenile dancers by applying the diversity of means and methods.

For example, the motivation of dancing partners remains important in sports dances; it is important that the dancers of the couple strive for the same sports goal or their goals are close [19, 20]. The highest sports results are reached if the trainer cooperates with the trainee in a creative way and the motivation of juvenile dancers is developed since the beginning of the sports activity [17, 21]. The confidence of athlete in the trainer and the selfconfidence are especially important and it encourages the further sports activity. Creative implementation of individual training programmes encourages the selftraining of the trainee mostly and it allows understanding the consistent patterns and coincidences of alternation of athlete as a dynamical complex system and reacting to the changing environment independently creatively [21-23]. Moreover, it is especially relevant that the athlete's training programme is adequate to both their sports abilities and their needs and wishes. There are no theoretical studies on these issues. The training of sports dancers is often intuitive because there are no prepared and science-based sports training models for dancers of different ages and mastery. Thus, there is a relevant scientific issue - in what way the needs of children should be considered, the diversity of methods and means should be applied and sports training programmes for juvenile dancers should be modelled in order to encourage the expression of their sport motivation. Taking into account these things, a hypothesis is raised in the work that the sports training model for junior (9-11) dancers that is based on the athlete's management theory accentuating the significance of the feedback strengthens the sport motivation $[15,16]$.

The purpose of the research - to verify the effectiveness of sports training programme on the expression of juvenile (9-11 years old) sports dancers sport motivation.

\section{Material and methods.}

Participants: three groups were chosen for a pedagogic experiment by applying the principle of the probabilistic serial selection from the list of groups of the chosen sports dance club "Toro" of Kaunas and Kazlų Rūda by drawing lots: it is EG-1 - the first experimental group, EG-2 - the second experimental group, CG - the control group. In total, 54 juvenile (9-11 years old) sports dancers participated in the experiment. Each group consisted of 18 participants (9 girls and 9 boys). In order to ensure the homogeneity of the experimental and control groups, all the participants were chosen from one dance sport club "Toro". In order to ensure the homogeneity of the experimental (EG-1 and EG-2) and control (CG) groups, both the age and sex of the researched and their mastery were considered; it complied with qualification category $\mathrm{E} 4$ and it means that the juvenile dancers can dance four dances at competitions: slow waltz, quickstep, cha-chacha and jive. Before starting testing, verbal agreements from parents of the children-participants for the experimental programme were obtained. The respondents that participated in the research were informed that the obtained data would be used for scientific goals only and provided in a general way in order not to identify any concrete persons. The data of these persons chosen for the statistical analysis of results complied with all the requirements for the research because the principles of the voluntary basis and anonymity were observed:

- the researched agreed to participate in the research voluntarily and answered all the asked questions;

- $\quad$ it was also tried to obtain open answers from each respondent and avoid any influence of other persons or their attitudes on the answers.

Organization of the research: the motivation of juvenile (9-11 years old) sports dancers was measured with the sport motivation scale (SMS) [24]. This scale was compiled on the basis of the theory of decision [25, 26] stating that the motivation has two sources of origin: the internal and the external ones. The sport motivation scale consists of 22 statements divided into 6 subscales, four in each: internal motivation - to find out; internal motivation - to strive for perfection; internal motivation - to experience; external motivation - to identify, synchronize; external motivation - direct external regulation; amotivation. Answering to each statement, the respondents had to choose the variants of their answer by using a 5-point Likert-type scale from 1 to 5 where 1 means „absolutely no “ and 5 - „absolutely yes“. After adapting this questionnaire [27] to the young athletes, the internal compatibility of scales and subscales was evaluated. The coefficient of internal consistence Cronbach alpha ranged between 0,64 and 0,82 in most subscales of the sport motivation scale. The internal consistence of statements is expressed when the meaning of the coefficient Cronbach alpha exceeds 0,6 [28]. Thus, it can be stated that the internal compatibility of methodical statements is sufficient.

A pedagogic experiment with an independent variable - different sports training programmes for two experimental (EG-1 and EG-2) groups and one control (CG) group was performed during the research. The dependent variable was the sport motivation of the dancers. By using a pedagogic experiment, it is mostly tried to check the quality of the content of practice compiled by the researcher. The experiment was performed under real conditions and the training process was organized in a small group.

During the pedagogic experiment, the scheme of research of three groups was applied by using the initial and final measurements. A survey questionnaire was used at the beginning and at the end of the experiment in order to determine the effect of practice performed with different methods and means. The initial research was performed before and the final research - after the pedagogic experiment during the trainings.

According to the recommendations of the researchers [1-12], the experiment lasted for 12 weeks. The sports dancers of all the groups had practice three times a week (1,5 hours), but the contents of their sports training 
programme were different.

The dancers of the experimental group (EG-1) had athletic training practice with dominant active games and relay races as well as track-and-field athletics and rhythmic gymnastics exercises once per week. Meanwhile, the dancers of the experimental group (EG-2) had general aerobics and aerobic gymnastics practice once a week. The juvenile dancers participating in the pedagogic experiment were enabled choosing the alternative content of practice (considering their wishes, boring exercises were replaced with other ones, but included in the programme again after some time) according to their needs in order to create favourable conditions to develop the sport motivation.

The exercises for the training of motor abilities also reflected in the introductory part of usual sports dance practice (about 20 minutes) in the experimental group (EG-1) and experimental group (EG-2).

The dancers of the control group (CG) were trained three times a week under usual conditions according to the sports dance improvement programme compiled by their coach. The technical training dominated in the practice. The same coach led practices for all the groups.

Statistical analysis: the statistical research data analysis was performed by using the SPSS (Statistical Package for Social Sciences, version 22.0) programme package. Kholmogorov - Smirnov test and Wilcoxon Z criterion were used for the descriptive index analysis in order to compare two independent samples. Taking into account that the data did not have any normal distribution, the non-parametric Wilcoxon $Z$ criterion was chosen for the evaluation of statistical significance between two groups. Comparing the results of two groups, the statistical significance of differences between the evaluations of sport motivation indexes in individual groups was calculated. The reliability of differences between appropriate indexes was considered statistically significant when $\mathrm{p}<0,05$.

\section{Results.}

The goal of the research was to compare the results of the expression of sport motivation in juvenile (9-11 years old) dancers from experimental groups EG-1, EG-2 and control group CG. We were especially interested in the influence of sports training programme on juvenile (9-11 years old) dancers sport motivation from groups EG-1 and EG-2 that participated in the pedagogic experiment. The obtained results show that the expression of the internal motivation-indicating subscales increased statistically significantly for the dancers from groups EG-1 and EG-2 in the 12-week period of the pedagogic experiment: „to find out" $(Z=-3,193, p=0,001-E G-1 ; Z=-3,453, p$ $=0,001-\mathrm{EG}-2)$, „to strive for perfection“ ( $\mathrm{Z}=-3,533$, $p=0,000-E G-1 ; Z=-3,760, p=0,000-E G-2)$, ,to experience" $(Z=-2,976, p=0,003-E G-1 ; Z=-2,976, p$ $=0,003-E G-2)$. During the period of the experiment, the intensity of subscales of the external motivation increased statistically significantly for the dancers from groups EG-1 and EG-2: „direct external regulation“ $(\mathrm{Z}=-2,111$,
$p=0,035-E G-1 ; Z=-2,724, p=0,006-E G-2)$, ,to identify, synchronize“ ( $Z=-3,205, p=0,001-E G-1$ gr.; $Z$ $=-3,020, p=0,003-E G-2)$. The expression of subscales of the internal motivation ,to find out" $(Z=-3,071, p=$ $0,002)$ and external motivation „to identify, synchronize“ ( $Z=-2,565, p=0,010)$ increased for the dancers from the control group. The intensity of the subscale „amotivation“ did not change statistically significantly in the 12-week period of the pedagogic experiment $(p>0,05)$. It was determined that the internal motivation-indicating subscale "to strive for perfection" was mostly expressed for juvenile (9-11 years old) dancers.

The alternation of acceptance of the statements of the sport motivation subscale "to strive for perfection" for juvenile (9-11 years old) sports dancers in the 12-week period of the experiment is provided in Table 2.

The acceptance of the following statements of the subscale increased significantly for the dancers of groups EG-1 and EG-2 in the 12-week period of the model pedagogic experiment (Table 2): When I dance, I feel a pleasure by learning new moves (increase by 1,89 points (17 per cent) - EG-1, 0,55 point (11 per cent) - EG2), I dance because I feel a pleasure by improving my weaknesses (increase by 0,5 point (11 per cent) - EG-1, 0,67 point (17 per cent) - EG-2 ), I dance because I feel a pleasure by learning new moves I was unable to perform before (increase 0,84 point (22 per cent) - EG-1, 0,61 point (11 per cent) - EG-2.

\section{Discussion.}

Our research is one of few researches paying attention to the peculiarities of the expression of sport motivation of juvenile (9-11 years old) dancers and trying to evaluate whether the effectiveness of training means and methods and a proper choice of the contents of practices according to the needs of junior dancers can encourage the expression of sport motivation. A hypothesis was raised that the athlete's management theory based on the sports training programme for juvenile (9-11 years old) dancers strengthens the sport motivation. The results of the research obtained during the pedagogic experiment allow thinking that the hypothesis was confirmed. It was determined that the application of the sports training programme for juvenile dancers with the diversity of methods and means can be used successfully to strengthen the expression of their sport motivation.

Meanwhile, taking into account the insights of previous studies, it can be assumed that the motivation is closely related with the results of learning [29, 30]. It depends on the sport motivation why juvenile athletes perform the same task differently under the same conditions or capable children perform the same task differently. For example, it was determined [31] that the technical training was dominant during dance sport practices, so monotonic, equal tasks can encourage exaggerated competition among dancers or even disinclination for doing sports.

Our data shows that the intensity of two external motivation-indicating subscales "direct external regulation" and "identify, synchronize" as well as 
Table 1. Mean evaluation of alternation of the subscales of motivation in juvenile (9-11 years old) sports dancers during the 12-week period of the experiment in points $(n=54)$.

\begin{tabular}{|c|c|c|c|c|c|}
\hline $\begin{array}{l}\text { Subscales of } \\
\text { motivation }\end{array}$ & $\begin{array}{l}\text { Researched group } \\
(n=54)\end{array}$ & $\begin{array}{l}\text { Before the } \\
\text { experiment }\end{array}$ & $\begin{array}{l}\text { After the } \\
\text { experiment }\end{array}$ & $\mathbf{Z}$ & $\mathbf{p}$ \\
\hline \multirow{3}{*}{$\begin{array}{l}\text { Internal motivation - } \\
\text { to find out }\end{array}$} & EG-1 $(n=18)$ & 9,17 & 11,22 & $-3,193$ & 0,001 \\
\hline & EG-2 (n=18) & 9,17 & 10,94 & $-3,453$ & 0,001 \\
\hline & $K G(n=18)$ & 9,16 & 9,94 & $-3,071$ & 0,002 \\
\hline \multirow{3}{*}{$\begin{array}{l}\text { Internal motivation - } \\
\text { to strive for perfection }\end{array}$} & EG-1 & 19,56 & 22,44 & $-3,533$ & 0,000 \\
\hline & $\mathrm{EE}-2$ & 19,54 & 22,11 & $-3,760$ & 0,000 \\
\hline & KG & 19,56 & 19,72 & $-1,342$ & 0,180 \\
\hline \multirow{3}{*}{$\begin{array}{l}\text { Internal motivation - } \\
\text { to experience }\end{array}$} & EG-1 & 6,72 & 8,44 & $-2,976$ & 0,003 \\
\hline & EG-2 & 6,71 & 7,94 & $-2,976$ & 0,003 \\
\hline & KG & 6,72 & 6,72 & 0,000 & 1,000 \\
\hline \multirow{3}{*}{$\begin{array}{l}\text { External motivation } \\
\text { - direct external } \\
\text { regulation }\end{array}$} & EG-1 & 15,44 & 15,94 & $-2,111$ & 0,035 \\
\hline & EG-2 & 15,45 & 16,33 & $-2,724$ & 0,006 \\
\hline & KG & 15,44 & 15,50 & $-1,000$ & 0,317 \\
\hline \multirow{3}{*}{$\begin{array}{l}\text { External motivation - } \\
\text { to identify, synchronize }\end{array}$} & EG-1 & 13,78 & 15,56 & $-3,205$ & 0,001 \\
\hline & EG-2 & 13,72 & 15,06 & $-3,020$ & 0,003 \\
\hline & KG & 13,78 & 14,50 & $-2,565$ & 0,010 \\
\hline \multirow{3}{*}{$\begin{array}{l}\text { Amotivation -non- } \\
\text { motivation }\end{array}$} & EG-1 & 10,17 & 10,17 & $-0,138$ & 0,890 \\
\hline & EG-2 & 9,89 & 10,00 & $-0,557$ & 0,577 \\
\hline & KG & 10,06 & 10,22 & $-1,134$ & 0,257 \\
\hline
\end{tabular}

Note: EG-1 - first experimental group, EG-2 - second experimental group, CG - control group

Table 2. Mean evaluation of alternation of acceptance of the statements of the subscale of the internal motivation "to strive for perfection" in juvenile (9-11 years old) sports dancers during the 12-week period of the experiment in points $(n=54)$.

\begin{tabular}{|c|c|c|c|c|c|}
\hline Statement & $\begin{array}{l}\text { Researched group } \\
(n=54)\end{array}$ & $\begin{array}{l}\text { Before the } \\
\text { experiment }\end{array}$ & $\begin{array}{l}\text { After the } \\
\text { experiment }\end{array}$ & Z & p \\
\hline \multirow{3}{*}{$\begin{array}{l}\text { When I dance, I feel a } \\
\text { pleasure by learning new } \\
\text { moves }\end{array}$} & EG-1 $(n=18)$ & 2,28 & 4,17 & $-2,724$ & 0,006 \\
\hline & $\mathrm{EG}-2(\mathrm{n}=18)$ & 3,28 & 3,83 & $-2,887$ & 0,004 \\
\hline & $K G(n=18)$ & 3,28 & 3,33 & $-1,000$ & 0,317 \\
\hline \multirow{3}{*}{$\begin{array}{l}\text { I dance because I feel a } \\
\text { pleasure by improving my } \\
\text { weaknesses }\end{array}$} & EG-1 & 3,44 & 3,94 & $-2,714$ & 0,007 \\
\hline & $\mathrm{EG}-2$ & 3,44 & 4,11 & $-2,972$ & 0,003 \\
\hline & KG & 3,44 & 3,56 & $-1,414$ & 0,157 \\
\hline \multirow{3}{*}{$\begin{array}{l}\text { I dance because I feel a } \\
\text { pleasure by learning new } \\
\text { moves I was unable to } \\
\text { perform before }\end{array}$} & EG-1 & 3,22 & 4,06 & $-3,035$ & 0,002 \\
\hline & EG-2 & 3,22 & 3,83 & $-2,810$ & 0,005 \\
\hline & KG & 3,22 & 3,22 & 0,000 & 1,000 \\
\hline \multirow{4}{*}{$\begin{array}{l}\text { I dance because I feel a } \\
\text { pleasure by performing } \\
\text { new and complicated dance } \\
\text { moves }\end{array}$} & EG-1 & 3,22 & 3,61 & $-2,333$ & 0,020 \\
\hline & EG-2 & 3,28 & 3,56 & $-1,633$ & 0,102 \\
\hline & KG & 3,22 & 3,22 & 0,000 & 1,000 \\
\hline & EG-1 & 3,06 & 3,22 & $-1,342$ & 0,180 \\
\hline \multirow{2}{*}{$\begin{array}{l}\text { I dance because I like dance } \\
\text { music very much }\end{array}$} & EG-2 & 3,06 & 3,22 & $-1,342$ & 0,180 \\
\hline & KG & 3,06 & 3,06 & 0,000 & 1,000 \\
\hline \multirow{3}{*}{$\begin{array}{l}\text { I feel a big pleasure } \\
\text { performing moves when } \\
\text { dance music is played }\end{array}$} & EG-1 & 3,33 & 3,44 & $-1,414$ & 0,157 \\
\hline & EG-2 & 3,33 & 3,56 & $-1,633$ & 0,102 \\
\hline & KG & 3,33 & 3,33 & 0,000 & 1,000 \\
\hline
\end{tabular}

Note: EG-1 - first experimental group, EG-2 - second experimental group, CG - control group 
subscale of the internal motivation "strive for perfection" was the biggest in juvenile (9-11 years old) dancers that participated in the 12-week experiment at the beginning of the model pedagogic experiment. The expression of other subscales of the internal motivation ,to find out“ and „to experience“ was lower $(p<0,05)$. Meanwhile, it is emphasized in the study [32] performed with cricket players-teenagers that the expression of the internal motivation-indicating subscales ,to find out", „to strive for perfection“ is equally intensive and the expression of the subscale „to experience“ is a little lower.

Taking into account the results of the pedagogic experiment, we can state that the application of the diversity of the contents of sports training in dance sport practices is related with the encouragement of the expression of sport motivation in juvenile (9-11 years old) dancers. During the 12-week period of the experiment, the statistically significant differences became clear in the dancers of the experimental (EG-1 and EG-2) groups $(p<0,05)$ according to all the internal motivation-indicating subscales: ,to find out“, „to strive for perfection“, „to experience“. Thus, it is possible to support the conclusions of other researchers $[27,33]$ that it is purposeful to implement similar sports training programmes with the dominant diversity of means and methods; moreover, one of the most important factors that encourage the sport motivation is the coach's ability to realize the contents of practices in a qualitative and creative way.

Nevertheless, there is a contradiction in the activity of sports training what should be preferred - striving for good sport results or development of children's personality realizing their needs [27]. However, the results of our research revealed that it is possible to combine them because the content of sports training according to the needs of juvenile dancers increased their sport motivation expression indexes. Nevertheless, it is stated that the motivation of victories is also very important in sport as it is one of strains of the activity motivation related with a need to improve their own skills and strive for the sport result $[18,25,26]$.

It is indicated in similar studies that girls and boys are very active in the period of the middle childhood and participate willingly in various sports activities [8]. The data of our research reveals that the internal motivation subscale expression indexes improved statistically significantly in the 12 -week period of the pedagogic experiment $(p<0,05)$ both in the groups of girls and boys that participated in the experiment.

Before the experiment, the internal motivation of dancers-girls and dancers-boys from these groups did not differ statistically significantly $(\mathrm{p}>0,05)$. However, there are studies that determined statistically significant differences between the internal motivations of the researched of different sexes: for example, it is indicated [34] that the motivation of teenagers-boys to do sports is higher than that of girls. Our research confirmed that the effectiveness of training means and methods and a proper choice of the contents of practices according to the needs of juvenile dancers could have a positive influence on the sport motivation.

Nevertheless, it is necessary to mention a few significant limitations of our research. First, the sample of the researched was formed from the junior dancers of one sports dance club only. We think the representation of a bigger sample should be strived for similar researches in the future. Second, the sports training programme was applied to the juvenile (9-11 years old) dancers, so it can be doubted about the generalization of the results of researches for other samples. Third, the results were provided before and after the pedagogic experiment; it may be purposeful to provide data of similar studies after half a year or even after a longer period in order to evaluate a long-lasting effect of the sports training programme. We think these drawbacks hinder the possibilities to interpret the results of our research more widely.

Taking into account these facts, it can be stated that other studies are necessary in order to reveal how long young athletes are able to stabilize their sport motivation during trainings or competitions after the sports training programme. We think the analysis of effectiveness of means and methods of the sports training programme with attention to the motivation of juvenile dancers and individualization of the programme could be a further trend of researches. The researchers should also consider in the future whether sports training programmes with similar contents are always purposeful and proper to develop the constructs of sport motivation in juvenile dancers. Similar long-lasting studies are also necessary so that coaches and young athletes understand that they can be effective if they encounter any difficulties and lose their motivation for doing sports.

\section{Conclusions}

To sum up, it can be stated that the effect of the sports training programme on the expression of sport motivation in juvenile (9-11 years old) sports dancers was determined during the pedagogic experiment: the diversity of methods and means applied during the experiment had a positive influence on the motivation of juvenile dancers. After the sports training programme, there were statistically reliable changes in the both experimental groups and they were related with the effect of the sports training programme according to the expression of the internal motivation-indicating subscales: „to find out“ „, to strive for perfection“ „to experience“ and the external motivationindicating subscales: „direct external regulation“ and „to identify, synchronize“.

\section{Conflict of interests:}

The authors declare that there is no conflict of interests. 


\section{References:}

1. Kḷonova A, Kḷonovs J. Heart Rate and Energy Consumption During Standard Sport Dancing. LASE Journal of Sport Science, 2010; 1(1):48-52.

2. Kḷonova A, Kḷ̆onovs J, Giovanardi A, Cicchella A. Smart motion capture system measuring movements of professional standard sports dancers in promenade position. LASE Journal of Sport Science. 2011; 2:26-32.

3. Biddle SJH, Gorely T, Marshall SJ, Murde I, Cameron N. Physical activity and sedentary behaviours in youth: issues and controversies. The Journal of the Royal Society for the Promotion of Health, 2004; 124(1):29-33.

4. Trost SG, Rosenkranz RR, Dzewaltowski D. Physical activity levels among children attending after-school programs. Medicine and Science in Sports and Exercise, 2008; 40(4):622-629.

5. Liiv H, Jürimäe T, Mäestu J, Purge P, Hannus A, Jürimäe J. Physiological characteristics of elite dancers of different dance styles. European Journal of Sport Science, 2014; 14(1):429-36.

6. Whitehead S, Biddle S. Adolescent girls' perceptions of physical activity: A focus group study. European physical education review, 2008; 14(2):243-262.

7. Abdelaziz YE, Harb AH, Hisham N. Textbook of Clinical Pediatrics. Philadelphia: Lippincott Williams \& Wilkins; 2012.

8. Armstrong N, Van Mechelen W. Paediatric exercise science and medicine. Oxford: Oxford University Press; 2008.

9. Flatters I, Hill LJ., Williams JH, Barber SE, Mon-Williams M. Manual control age and sex differences in 4 to 11 year old children. PloS one, 2014; 9(2):e88692

10.Kostić R, Miletić D, Jocić D, Uzunović S. The influence of dance structures on the motor abilities of preschool children. Facta Universitatis. Series Physical Education and Sport. 2003; 1(9):83-90.

11.Kautedakis Y, Hukam H, Metsios G, Nevill A, Giakas G, Jamurtas A, et al. The effects of three months of aerobic and strength training on selected performance-and fitnessrelated parameters in modern dance students. The Journal of Strength \& Conditioning Research, 2007; 21:808-812.

12.Radionov MV. Physical preparedness of junior dancers as mean of increase of sports result. Teoriia i praktika fizicheskoj kul'tury, 2011; 4:58-61. (in Russian)

13.Amado D, Sánchez-Miguel PA, Molero P. Creativity associated with the application of a motivationl intervention programme for the teaching of dance at school and its effect on the both genders. PLoS one, 2017; 12(3): e0174393

14.Hughes M, Franks I. Notational analysis of sport: Systems for better coaching and performance in sport. London: Ed. Routledge; 2004.

15.Wrisberg CA. Sport skill instruction for coaches. Champaign, IL: Human Kinetics; 2007.

16.Roemmich JN, Lambiase MJ, McCarthy TF, Feda DM, Kozlowski KF. Autonomy supportive environments and mastery as basic factors to motivate physical activity in children: a controlled laboratory study. International Journal of Behavioral Nutrition and Physical Activity, 2012; 9:16-20. doi:10.1186/1479-5868-9-16

17. Vallerand RJ. A hierarchical model of intrinsic and extrinsic motivation for sport and physical activity. In: Hagger MS, Chatzisarantis NL, (ed.) Intrinsic motivation and self- determination in exercise and sport. Champaign, IL: Human Kinetics; 2007. P. 255-279.

18. Malinauskas R. Applied sport psychology. Kaunas: LKKA; 2010. (in Lithuanian)

19.Karpenko LA, Sivitskiy VA. Basic training in parquet dance. Nauchno-teoreticheskiy zhurnal «Uchenyye zapiski», 2009; 5(51): 36-40. (in Russian)

20.Qian Z. The Review and Motivation Analysis of Dancesport Development in China. Zhejiang Sport Science, 2013; 1:1520

21.Moreno-Murcia JA, Cervelló EM, González-Cutre D. Young athletes' motivational profiles. Journal of Sports Science and Medicine, 2007; 66: 172-179.

22.Ryan RM, Deci EL. Active human nature. Self-determination theory and the promotion and maintenance of sport, exercise, and health. In. Hagger MS, Chatzisarantis NL, (ed.) Intrinsic motivation and self-determination in exercise and sport. Champaign, IL: Human Kinetics; 2007. P. 1-19.

23.Jaakkola T, Washington T, Yli-Piipari S. The association between motivation in school physical education and selfreported physical activity during Finnish junior high school: The self-determination theory approach. European Physical Education Review, 2013; 19(1):127-141.

24.Pelletier LG, Fortier MS, Vallerand RJ, Tusan KM, Briere NM, Blais MR. Toward a new measure of intrinsic motivation, extrinsis motivation and amotivation in sports: The Sport Motivation Scale (SMS). Journal of sport and Exercise Psychology, 1995; 17(1):35-53.

25.Deci EL, Ryan RM. Intrinsic motivation and selfdetermination in human behavior. New York: Plenum; 1985.

26.Deci EL, Ryan RM. The „what“ and „why“ of goal pursuits: Human needs and the self-determination of behavior. Psychological Inquiry, 2000; 11(4):227-268.

27.Grajauskas L. Modelling of young orienteerers' (at age of 12-14) training by applying diversity of training means and methods. Doctoral dissertation. Šiauliai: Šiaulių universitetas; 2008. (in Lithuanian)

28.Pukènas K. Qualitative data analysis SPSS program. Kaunas: LKKA, 2009. (in Lithuanian)

29.Daniels LM, Pekrun R, Stupnisky RH, Haynes TL, Perry RP, Newall NE. A longitudinal analysis of achievement goals: From affective antecedents to emotional effects and achievement outcomes. Journal of Educational Psychology, 2009; 101(4):948-963.

30.Puente-Diaz R. The effect of achievement goals on enjoyment, effort, satisfaction and performance. International Journal of Psychology, 2012; 47(2):102-110.

31.Ušpurienè BA. Modeling of coaching in juvenile sports dancers (9-11) years old. Doctoral dissertation. Kaunas: LSU; 2015. (in Lithuanian)

32.Teo EW, Khoo S, Wong R, Wee EH, Lim BH, Rengasamy SS. Intrinsic and extrinsic motivation among adolescent tenpin bowlers in Kuala Lumpur, Malaysia. Journal of Human Kinetics, 2015; 45(1):241-251.

33.Kerr JH. Motivation and emotion in sport: Reversal theory. Hove and New York: Psychology Press; 2014.

34.Zahariadis PN, Tsorbatzoudis H, Grouios G. The sport motivation scale for children: preliminary analysis in physical education classes. Perceptual and motor skills, 2005;101(1):43-54. 


\section{Information about the authors:}

Uspuriene B.A. (Corresponding author);; Dr. (Pedagogy),; http://orcid.org/0000-0002-5176-3513 ; aiste.uspuriene@Isu.It; Lithuanian Sports University; 6 Sporto street, LT-44221, Kaunas, Lithuania.

Sniras S.A.; Dr. (Pedagogy), Assoc. professor; http://orcid.org/0000-0003-0838-2317; Lithuanian Sports University; 6 Sporto street, LT-44221, Kaunas, Lithuania.

Cite this article as: Uspuriene BA, Sniras SA. Effect of sports training programme on juvenile sports dancers motivation. Pedagogics, psychology, medical-biological problems of physical training and sports, 2018;22(3):163-169. doi:10.15561/18189172.2018.0308

The electronic version of this article is the complete one and can be found online at: http://www.sportpedagogy.org.ua/index.php/PPS/issue/archive

This is an Open Access article distributed under the terms of the Creative Commons Attribution License, which permits unrestricted use, distribution, and reproduction in any medium, provided the original work is properly cited (http://creativecommons.org/licenses/by/4.0/deed.en).

Received: 08.05.2018

Accepted: 01.06.2018; Published: 30.06.2018 